\author{
REA - Revista de estudos ambientais (Online) \\ v.17, n. 2, p.60-73, jul./dez. 2015
}

F U R B

\title{
PLACAS PARA FORRO PRODUZIDAS COM COMPÓSITO DE GESSO E EPS RECICLADOS
}

\author{
Abrahão Bernardo Rohden e Rodolfo Antônio Mecabô
}

\begin{abstract}
Resumo: O gesso e o poliestireno expandido (EPS) são amplamente utilizados na construção civil. Apesar de serem materiais conhecidos há bastante tempo, as tecnologias de reintrodução dos rejeitos destes materiais na cadeia produtiva ainda encontram desafios. O objetivo deste estudo constituiu-se no desenvolvimento de placas para serem empregadas em forro a partir de um compósito de gesso e EPS reciclados. A metodologia utilizada consistiu no beneficiamento e na caracterização do gesso reciclado, comparando o mesmo ao gesso comercial e as exigências normativas. Foram produzidas pastas com o gesso reciclado buscando compreender seu comportamento em função da relação água/gesso. A partir do comportamento da pasta foi então produzido o compósito com adição de três teores de EPS reciclado de 5 , 10 e $15 \mathrm{~g}$. Moldaram-se, então, placas com as quais se realizou os ensaios de resistência à tração na flexão e massa específica. Os resultados mostram que as pastas de gesso reciclado com relação água:gesso igual a 1 e os compósitos com 5 e $10 \mathrm{~g}$ de EPS reciclado são adequados para produção de placas para forro quanto à resistência à tração na flexão e massa específica.
\end{abstract}

Palavras-chave: Resíduos. Gesso. EPS. Placas. Forro.

\section{Introdução}

O segmento gesseiro no Brasil encontra-se em expansão, com uma taxa de crescimento anual média de $15 \%$ no período de 2008 a 2013 (SINDUSGESSO, 2014). Segundo Pinheiro (2011) o crescimento do segmento se deve principalmente à disseminação de sistemas construtivos alternativos, ao baixo custo do gesso e ao alto teor de pureza das jazidas de gipsita nacional. A Figura 1 apresenta o consumo histório de chapas para drywall, sistemas construtivos que emprega o gesso, no Brasil. As regiões Sudeste e Sul lideram o mercado de drywall, consumindo $76 \%$ do total (ASSOCIAÇÃO BRASILEIRA DO DRYWALL, 2015).

Além do drywall a utilização do gesso está cada vez maior, pois sua pasta é vista pelas construtoras como um material alternativo, de qualidade e de baixo custo para ser aplicado em revestimentos internos de paredes. Além do custo reduzido, verificase maior produtividade por parte dos aplicadores, devido à rapidez de execução, e um bom acabamento final, podendo ser aplicado o sistema de pintura sem a necessidade de aplicação da massa corrida (TAVARES et al., 2010). O gesso também é utilizado como material de fundição na produção de placas de forro, sancas, molduras e outras peças de acabamento (MONTEIRO; MELO; UCHÔA, 2010).

No ano de 2013 no Brasil a extração do minério de gipsita foi da ordem de 3,3 milhões de toneladas por ano. Deste total $57 \%$ são destinados ao consumo direto do gesso para aplicação na construção, 30\% são destinados ao setor cimenteiro e 11\% ao setor agrícola. O polo gesseiro de Araripe (PE) é responsável por $85 \%$ da produção nacional de gipsita (BRASIL, 2013; PINHEIRO, 2011).

$\mathrm{Na}$ fase de aplicação no canteiro de obras há grande geração de resíduo. Um dos principais motivos segundo Nita et al. (2004) para o grande volume de resíduo de gesso se deve à alta velocidade de endurecimento da pasta de gesso aplicada como revestimento. Estima-se que o índice de desperdício seja equivalente a $45 \%$ de todo o gesso utilizado.

Monteiro,Melo e Uchôa (2010) realizaram um estudo em seis construtoras e quantificaram a geração de resídos na construção civil de Maceio (AL). Segundo os autores a geração de resíduos é de aproximadamente $50 \%$ para o gesso aplicado em pasta e de $5 \%$ para placas

${ }^{1}$ E-mail: abrcivil@gmail.com

FURB - Universidade Regional de Blumenau, Departamento de Engenharia Civil. CAMPUS II - Complexo Tecnológico. Rua São Paulo, 3250 - Itoupava Seca. CEP 89.030-000 - BLUMENAU - SC, Brasil 
fundidas aplicadas como forro. Na Figura 2

(a) é mostrado o resíduo de placas de gesso utilizado como revestimento de forro enquanto na Figura 2 (b) o resíduo gerado na aplicação do gesso em pasta aplicado como revestimento interno em paredes.

Figura 1 - Consumo histórico anual de chapas para drywall no Brasil

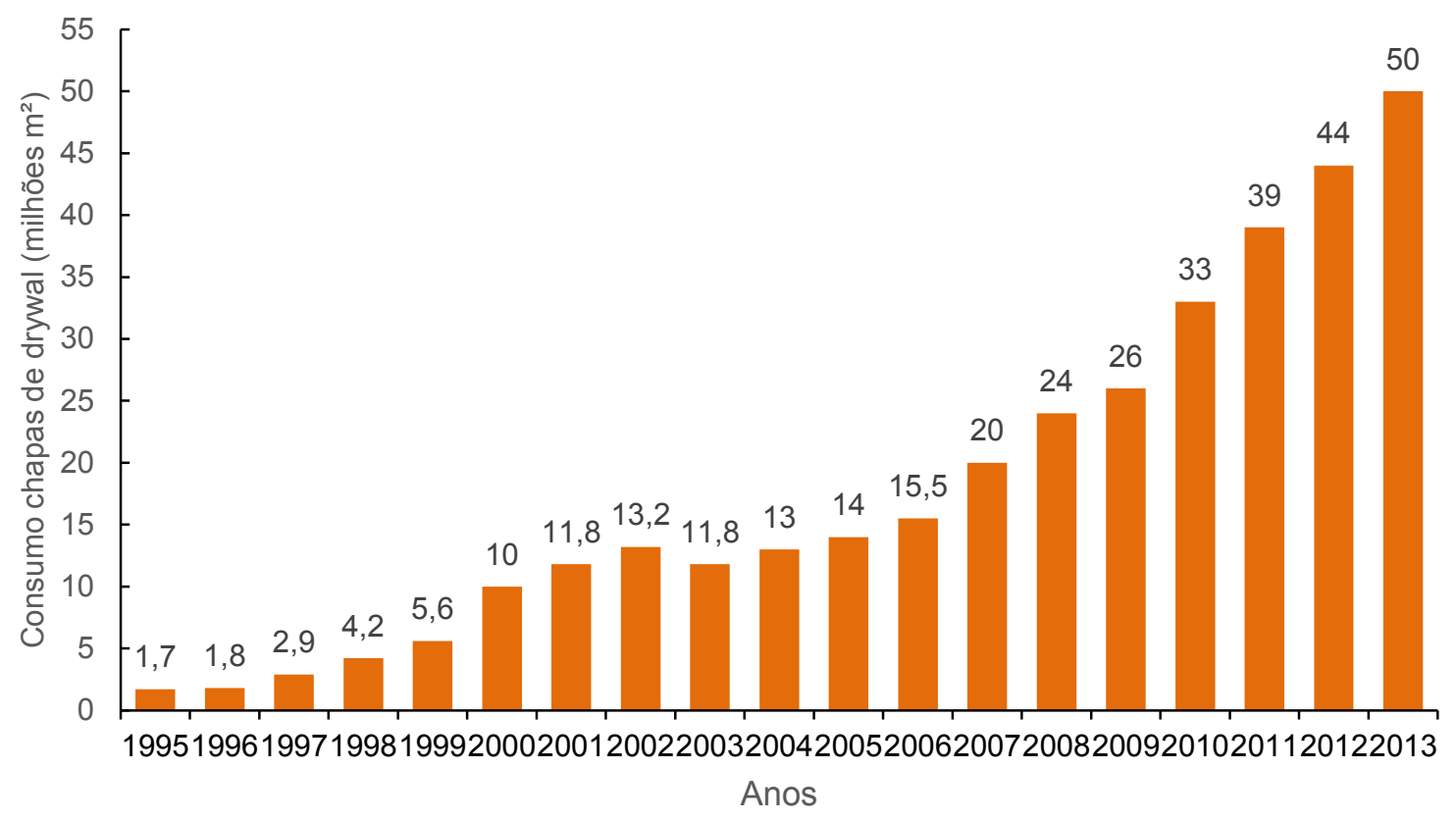

Fonte: Associação Brasileira do Drywall (2015)

Figura 2 - Exemplos de geração de resíduos de gesso (a) de recorte de placas utilizadas como revestimento de forro e (b) da aplicação do gesso em pasta no revestimento de parede
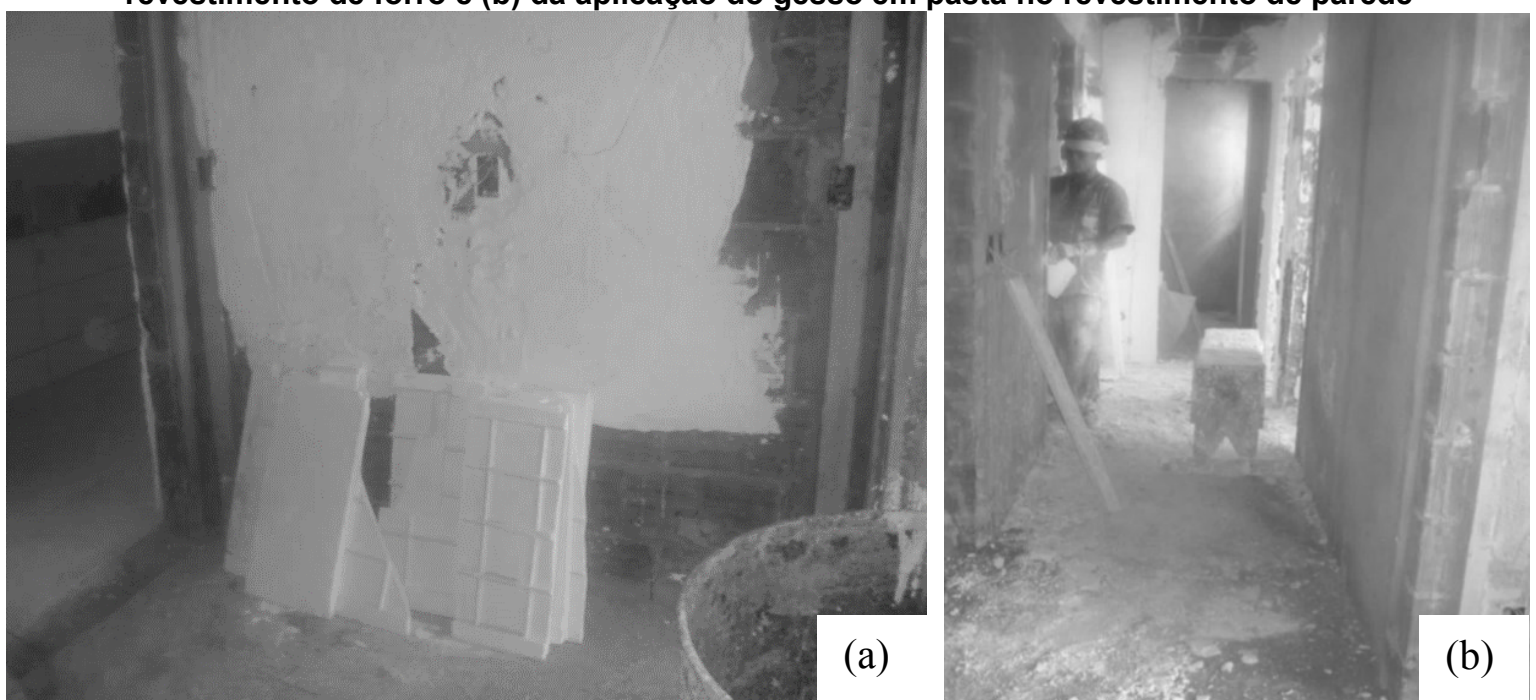

Fonte: Monteiro, Melo e Uchôa (2010)

As características físico-químicas do resíduo exigem cuidados especiais na sua disposição final, devido ao seu potencial tóxico, à liberação de gases inflamáveis, ao risco de contaminação do solo e do lençol freático, bem como em razão das restrições aos percentuais de uso em agregados reciclados oriundos dos resíduos da construção civil (PINHEIRO, 2011). O gesso em contato com umidade e condições anaeróbicas, com baixo $\mathrm{pH}$, e sob ação de bactérias redutoras de sulfatos, condições presentes em muitos aterros sanitários e lixões, pode formar gás sulfídrico $\left(\mathrm{H}_{2} \mathrm{~S}\right)$, que 


\section{REA - Revista de estudos ambientais (Online)}

v.17, n. 2, p.60-73, jul./dez. 2015

possui odor característico de ovo podre, é tóxico e inflamável (MOURA et al., 2014). Os resíduos de gesso depositados de forma irregular em terrenos baldios contaminam o

Entretanto, a reversibilidade de suas reações de transformação possibilita, por meio de um processo simples de reciclagem, a inserção do resíduo nos diferentes setores da sua cadeia produtiva (PINHEIRO, 2011). A resolução $n^{\circ} 307$ (CONAMA, 2002) classificava o resíduo de gesso como classe C, sem tecnologia de reciclagem economicamente viável. Contudo em maio de 2011, a resolução $\mathrm{n}^{\circ} 431$ (CONAMA, 2011) definiu o gesso como classe $B$ na classificação dos resíduos de construção e demolição (RCD), classificando-o como reciclável. Ou seja, a partir desta data os resíduos de gesso devem agora ser reciclados (MOURA et al., 2014).

Para isso todos os resíduos de gesso devem ser coletados e armazenados em caixas com fundo impermeável ou em caçamba, nos canteiros de obra. O local de armazenagem deve ser seco. Devem ser separados de outros materiais como madeira, metais, papéis, restos de alvenaria e do lixo orgânico. Os resíduos devem ser destinados as áreas de transbordo e triagem (ATTs) licenciadas para receber resíduos de gesso (ASSOCIAÇÃO BRASILEIRA DO DRYWALL, 2012)

Desde o final dos anos de 1990, vêm sendo pesquisados métodos de reciclagem do gesso usado na construção civil basicamente em três frentes, para aproveitamento na indústria do cimento, na agrícultura e no próprio setor de transformação do gesso.

Nita et al. (2004) realizaram um dos primeiros trabalhos buscando a reciclagem de resíduos de gesso oriundos da construção civil e de sua reutilização como adições ao próprio gesso de construção. $O$ estudo foi realizado de duas formas: na forma de diidrato, finamente moído, em substituição ao gesso hemidrato natural e na forma de hemidrato, após moagem e calcinação à temperatura de $140^{\circ} \mathrm{C}$, como substituição ao gesso de construção. Os resultados obtidos foram satisfatórios nos ensaios de resistência à compressão quando comparados com 0 material original. Todavia, foi observado um aumento na consistência do gesso e aceleração do tempo de pega, o que pode ser corrigido com a adição de aditivos retardadores de pega.

Tavares et al. (2010) também pesquisaram 0 desempenho do gesso meio ambiente, pois o gesso libera íons $\mathrm{Ca}^{2+}$ e $\left(\mathrm{SO}_{4}\right)^{2-}$ que alteram a alcalinidade do solo e contaminam lençóis freáticos (NASCIMENTO; PIMENTEL, 2010).

reciclado utilizando misturas de 0,5 e $10 \%$ de gesso reciclado em argamassas de gesso para revestimento de paredes. Foram avaliadas a dureza superficial, a resistência à compressão e a aderência das argamassas com e sem a presença do gesso reciclado. $O$ referido estudo mostrou que a adição de resíduos não prejudica execessivamente as propriedades, sendo admissível até $10 \%$ de resíduo de gesso na produção da nova argamassa. O trabalho mostrou também que adição do gesso reciclado acelera a hidratação da pasta e consequentemente, diminui o tempo de pega reduzindo o tempo útil de aplicação. Diferentemente do estudo de Nita et al. (2004) no estudo de Tavares et al. (2010) o gesso reciclado não foi calcinado, apenas foi moido.

Já Nascimento e Pimentel (2010) realizaram estudo a cerca às características físicas e mecânicas do gesso reciclado atender às normas técnicas que estabelecem os critérios mínimos de aceitação do gesso para construção civil. Avaliaram-se no estudo o módulo de finura, a massa únitária, os tempos de inicio e fim de pega e também a dureza e a resistência à compressão do gesso reciclado. $O$ resíduo de gesso foi moído durante 5 horas em um equipamento de abrasão Los Angeles sendo então calcinado. A calcinação foi realizada em três temperaturas diferentes: 160,180 e $200^{\circ} \mathrm{C}$ durante 6 horas. $O$ estudo mostrou ser viável a utilização do gesso reciclado.

Ao avaliar a adequação do gesso reciclado às prescrições da NBR 13207 (ABNT, 1994), Moura et al. (2014) concluiram, no entato, que o gesso estudado não atendeu satisfatoriamente nenhuma das exigências para classificação como gesso de construção. No referido estudo o resíduo foi calcinado à temperatura de $150^{\circ} \mathrm{C}$ por 24 horas. O material foi moído em moinho de bolas de forma que sua granulometria fosse equivalente à do gesso comercial. De acordo com os autores o gesso reciclado segundo a metodologia adotada apresentou massa unitária inferior à mínima fixada pela norma, quantidade de $\mathrm{SO}_{3}$ (anidrido sulfúrico) inferior à mínima fixada pela norma, tempo de pega fora dos intervalos de classificação como revestimento ou fundição estabelecidos pela norma assim como dureza e resistência à compressão também inferiores ao mínimo. 
REA - Revista de estudos ambientais (Online) v.17, n. 2, p.60-73, jul./dez. 2015

Sales, Santos e Ribeiro (2014) avaliaram a resistência à tração na flexão e a aderência de pasta de gesso reciclado. $O$ resíduo de gesso foi triturado em britador de mandíbula em seguida levado a estufa a $200^{\circ} \mathrm{C}$ por período de 8 horas. $O$ resíduo foi peneirado na malha de $2 \mathrm{~mm}$. No estudo foi avaliada uma composição de $50 \%$ de gesso reciclado mais $50 \%$ de gesso comercial. O estudo concluiu que comparativamente ao gesso comercial a composição de gesso comercial mais gesso reciclavel apresentou redução de $6 \%$ na resistência à tração na flexão, já no ensaio de aderência houve um aumento de $82 \%$. Os autores resaltam que os resultados de aderência atendem à norma de resvestimento de paredes e tetos de argamassas inorgânicas (NBR 13528, ABNT 2010).

Os recorrentes problemas de não atendimento dos tempos de pega quando do emprego do gesso reciclado motivou o estudo realizado por Mesquita e Póvoas (2014). Os autores investigaram a influência de aditivo retardador de pega na pasta de gesso com resíduo de gesso calcinado. O estudo contemplou a substituição do gesso comercial por gesso reciclado nas proporções de 0, 10, 50, 90 e 100\%. O gesso reciclado foi moído e calcinado a $150^{\circ} \mathrm{C}$. O aditivo retardador de pega utilizado foi o citrato de sódio na proporção de 0,06\% em relação à massa de materiais secos. $O$ estudo concluiu que o citrato de sódio diminuiu a resistência à compressão de todas as misturas, e houve aumento do tempo de utilização nas misturas com 0, 10 e $50 \%$ de resíduo, enquanto para as misturas com 90 e 100\% não houve variação significativa, todas com adição do retardador.

Segundo Medeiros et al. (2003) alguns materiais como o EPS ainda não podem ser reaproveitados ou reciclados devido às limitações técnicas e econômicas. Devido às características fisico-quimicas a reintegração do EPS ao ambiente faz-se de modo muito lento. O reuso desse polímero não é recomendado por questões de higiene e o reaproveitamento pela indústria não apresenta vantagens econômicas. As possibilidades de reaproveitamento são bastante restritas ou praticamente inexistentes, o que leva ao seu descarte após o uso trazendo sérias consequencias ao meio ambiente.

Medeiros et al. (2003) estudaram o reaproveitamento de EPS em sistema para isolamento térmico de coberturas. O EPS utilizado constitui-se de embalagens de alimentosreaproveitadas. $\mathrm{O}$ trabalho desmostra que o reaproveitamento do EPS a partir de embalagens de alimentos descartadas, é tecnicamente viável para o caso do isolamento térmico de coberturas. Evitando-se 0 descarte das embalagens através da sua integração a um sistema construtivo é uma forma simples, econômica e eficiente para redução dos danos ao meio ambiente.

Podem ser ainda citados outros usos para o EPS reciclado na construção civil. Siqueira, Stramari e Folgueras (2004) e Stocco, Rodrigues e Castro (2009) estudaram o EPS aplicado na confeção de blocos de concreto leve.

$\mathrm{O}$ objetivo deste trabalho foi 0 desenvolvimento e caracerização de um compósito de gesso e EPS reciclados destinado à produção de placas de forro.

\section{Material e métodos}

As matérias primas para moldagem das placas foram o gesso e polestireno expandido (EPS), ambos os materiais sendo provenientes de resíduos de canteiros de obras, coletados e previamente triados na área de transporte e transbodo (ATT) da cidade de Itapema (SC).

O estudo iniciou realizando a caracterização do gesso reciclado através da sua granulometria comparando o mesmo a uma marca comercial de gesso. Posteriomente foram produzidas pastas com gesso reciclado e comercial escolhendo-se uma pasta com boa trabalhabilidade. A partir da pasta escolhida foram então produzidos compositos com diferentes quantidades de EPS triturado (Figura 3).

Os ensaios realizados no gesso, na pasta de gesso e no compósito e as respectivas normas utilizadas são apresentados no Quadro 1. 


\section{REA - Revista de estudos ambientais (Online) v.17, n. 2, p.60-73, jul./dez. 2015}

Figura 3 - Fluxograma ilustrando as diferentes etapas realizadas nesta pesquisa

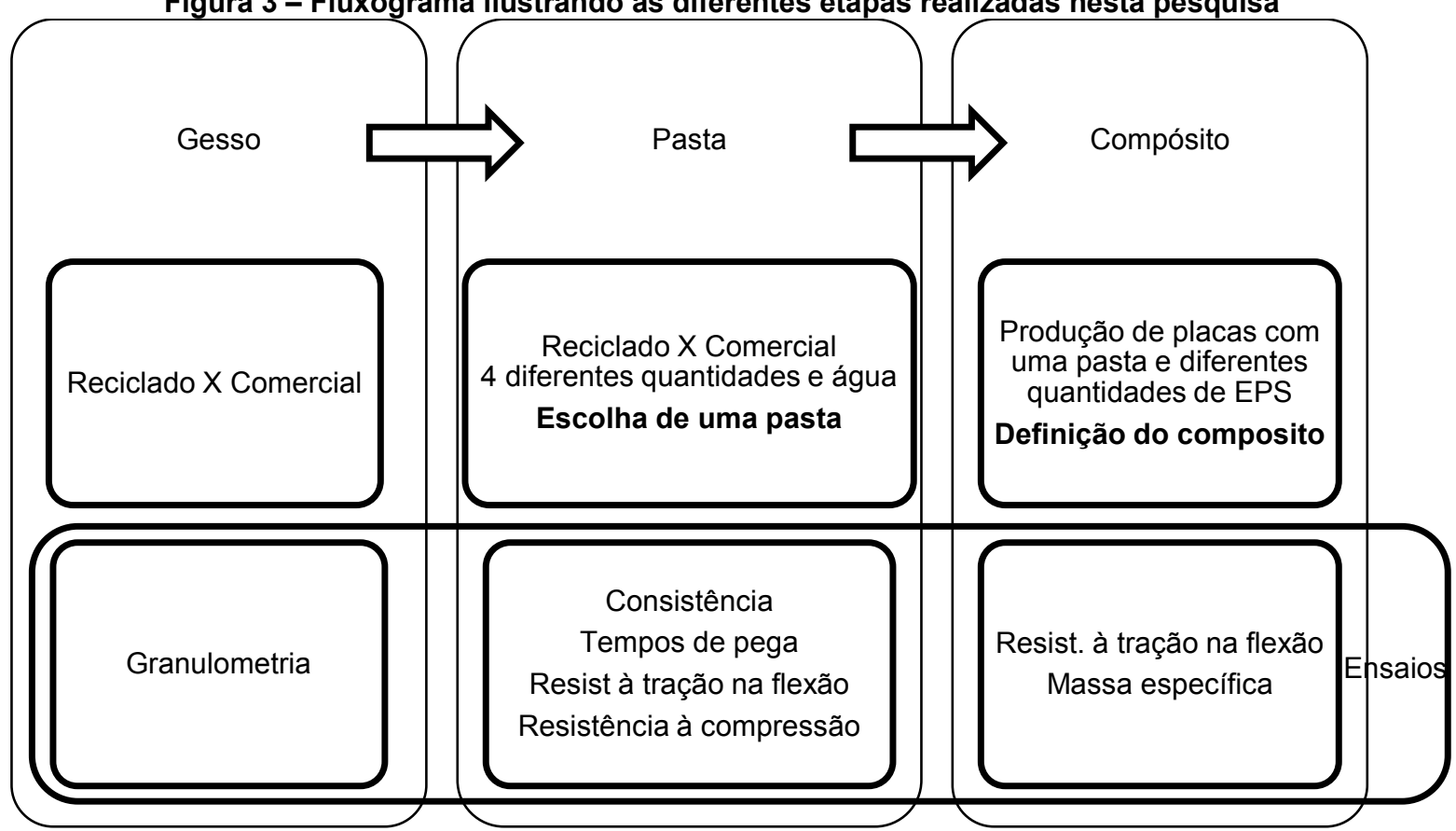

Fonte: Autores (2015)

Quadro 1 - Ensaios realizados em cada fase

\begin{tabular}{c|c|c}
\hline Gesso & Pasta & Compósito \\
\hline \multirow{4}{*}{ Granulometria } & Consistência do gesso & Resistência à tração na flexão \\
& NBR 13276 (ABNT, 2005) & NBR 12775 (ABNT, 1992) \\
\cline { 2 - 2 } NM 248 (ABNT, 2001) & Ínicio e fim de pega & \\
\cline { 2 - 2 } & NM 65 (ABNT, 2002) & Massa específica \\
\cline { 2 - 2 } & $\begin{array}{c}\text { Resistência à tração na flexão e } \\
\text { resistência à compressão }\end{array}$ & NBR 12775 (ABNT, 1992) \\
& NBR 13279 (ABNT, 2005) & \\
\hline
\end{tabular}

Fonte: Autores (2015)

\subsection{Gesso reciclado}

O material coletado na ATT, já selecionado e livre de impurezas e outros resíduos oriundos da construção civil, foram moídos e submetidos à máquina de ensaio Los Angeles por 30 minutos. O material foi então peneirado, sendo utilizada apenas a porcentagem passante na peneira $4,8 \mathrm{~mm}$, da qual foi realizada a análise granulométrica e determinado o módulo de finura. . Todo o material processado foi então calcinado em estufa a uma temperatura de $175^{\circ} \mathrm{C}$ durante um período de 3 horas.

A partir do gesso reciclado foram produzidas pastas descritas na Tabela 1 . Variou-se a quantidade de água de amassamento em cada uma das pastas produzidas. Diferentemente do que ocorre com o cimento quando se fixa a relação água/cimento no ensaio de determinação do tempo de pega, neste estudo a mesma não foi fixada. Foram determinados tempos de pega para diferentes proporções entre gesso e água (Tabela 1). Também foi realizado o ensaio de início de determinação dos tempos de pega com amostra de gesso comercial para se ter um parametro de comparação.

A consistência foi determinada segundo os requisitos da norma NBR 13276 (ABNT, 2005). Realizou-se o mesmo ensaio com as mesmas proporções descritas na Tabela 1 com amostra de gesso comercial para se comparar com o resíduo estudado.

Para determinação da resistência a tração na flexão do gesso reciclado, para cada mistura foram moldados 3 corpos de prova com dimensões de $4 \mathrm{~cm}$ de largura por $4 \mathrm{~cm}$ de altura por $16 \mathrm{~cm}$ de comprimento.

A resistência à compressão da pasta de gesso reciclado foi determinada a partir das metades dos corpos de prova utilizados no ensaio de resistência à tração na flexão. Assim para cada uma das pastas de gesso estudadas foram ensaiados seis corpos de prova. 


\section{REA - Revista de estudos ambientais (Online) v.17, n. 2, p.60-73, jul./dez. 2015}

\begin{tabular}{c|c|c}
\multicolumn{3}{c}{ Tabela 1 - Pastas de gesso estudadas } \\
\hline Pasta & Gesso $(\mathrm{g})$ & Água $(\mathrm{g})$ \\
\hline 1 & 1.000 & 500 \\
\hline 2 & 1.000 & 750 \\
\hline 3 & 1.000 & 1.000 \\
\hline 4 & 1.000 & 1.250 \\
\hline
\end{tabular}

Fonte: Autores (2015)

\subsection{Composito de gesso e EPS reciclados}

A partir da caracterização realizada do gesso reciclado incorporou-se à pasta de gesso o resíduo de EPS, produzindo-se placas delgadas com este compósito (Tabela 2). Os materiais foram pesados e misturados manualmente até se mostrarem homogeneamente misturados.
A mistura foi lançada em um molde métálico apresentado as dimensões de 33 centímetros de largura por 33 centímetros de comprimento e 13 milimetros de altura (Figura 4).

Tabela 2 - Compositos de gesso e EPS reciclados

\begin{tabular}{c|c|c|c}
\hline Composito & Gesso $(\mathrm{g})$ & Água $(\mathrm{g})$ & EPS $(\mathrm{g})$ \\
\hline 1 & 1.000 & 1.000 & 0 \\
\hline 2 & 1.000 & 1.000 & 5 \\
\hline 3 & 1.000 & 1.000 & 10 \\
\hline 4 & 1.000 & 1.000 & 15 \\
\hline
\end{tabular}

Fonte: Autores (2015)

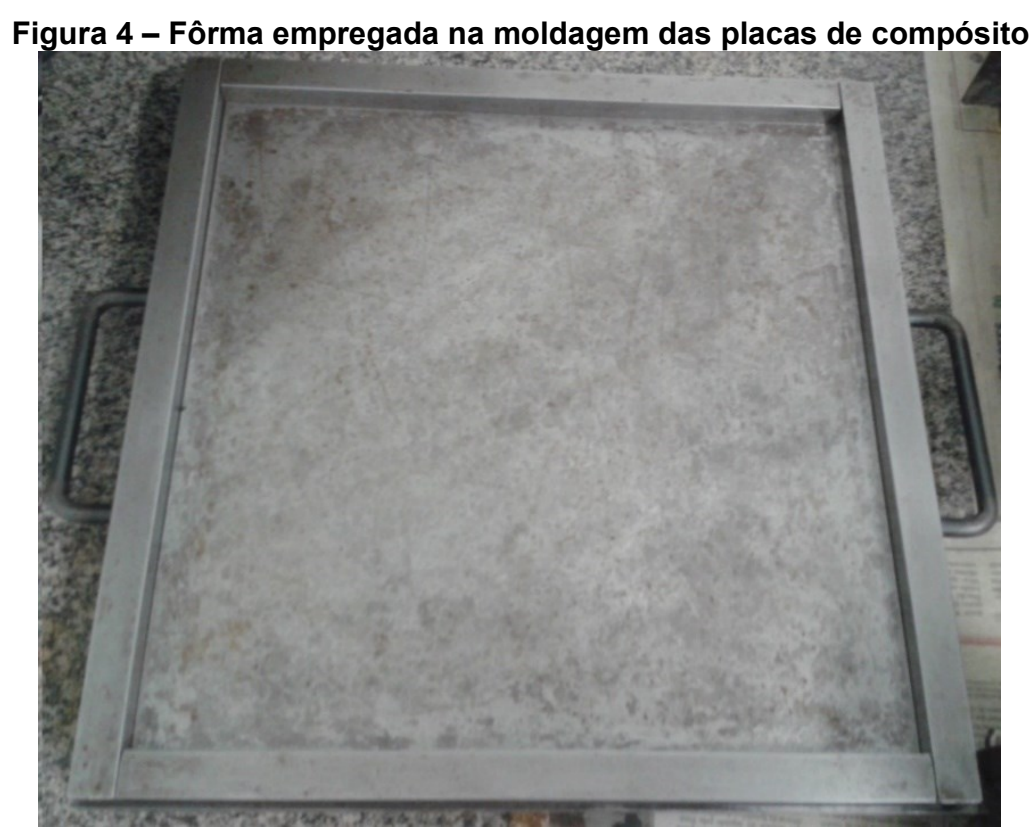

Fonte: Autores (2015)

A partir das placas moldadas foram extraídos corpos de prova para o ensaio de resistência a flexão e determinação da massa específica do compósito.

Para determinação da resistência a tração na flexão as placas moldadas foram cortadas sendo retirados quatro corpos de prova com dimensões de $120 \mathrm{~mm}$ de comprimento por $20 \mathrm{~mm}$ de largura. Os corpos de prova foram então submetidos ao ensaio de flexão a três pontos (Figura 5). Após ruptura os corpos de prova foram medidos com paquímetro na sua base e altura nos pontos onde houve o rompimento. Também foi realizada a determinação da massa específica das placas sendo utilizados dois corpos de prova. 


\section{REA - Revista de estudos ambientais (Online) v.17, n. 2, p.60-73, jul./dez. 2015}

Figura 5 - Dispositivo de apoio utilizado na determinação da resistência à tração na flexão

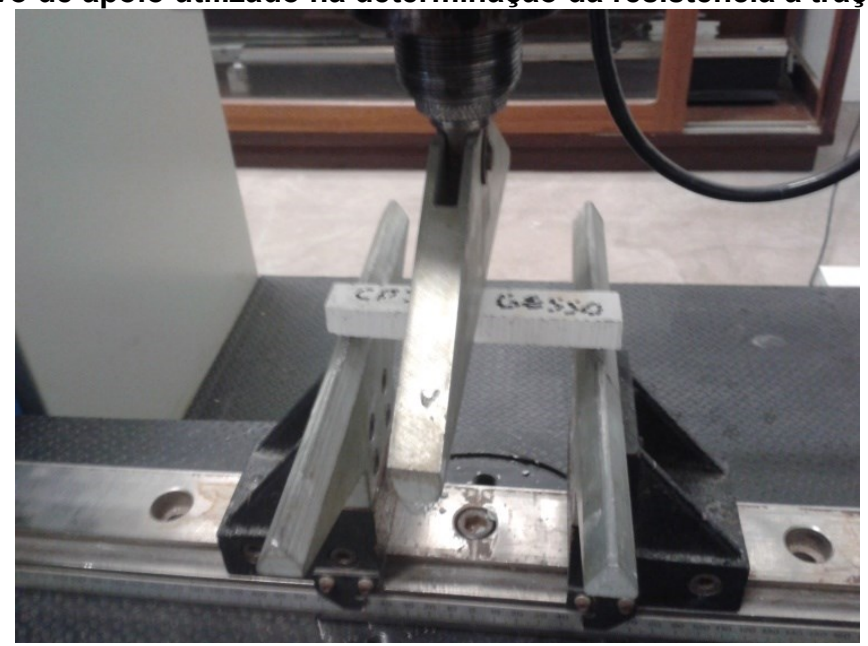

Fonte: Autores (2015)

\section{Resultados}

\subsection{Gesso reciclado}

\subsubsection{Granulometria do gesso reciclado}

Comparando-se a distribuição granulométrica do gesso reciclado com a do gesso comercial (Figura 6) pode-se afirmar que $o$ gesso reciclado apresenta um percentual passante acumulado pequeno nas peneiras mais finas. Enquanto mais de $90 \%$ do gesso comercial passa na peneira $0,3 \mathrm{~mm}$, somente $20 \%$ do gesso reciclado passa na peneira $0,3 \mathrm{~mm}$. Este fato se deve basicamente ao processo e ao equipamento de moagem utilizado neste estudo.

Figura 6 - Curva granulométrica do gesso reciclado após a moagem e gesso comercial

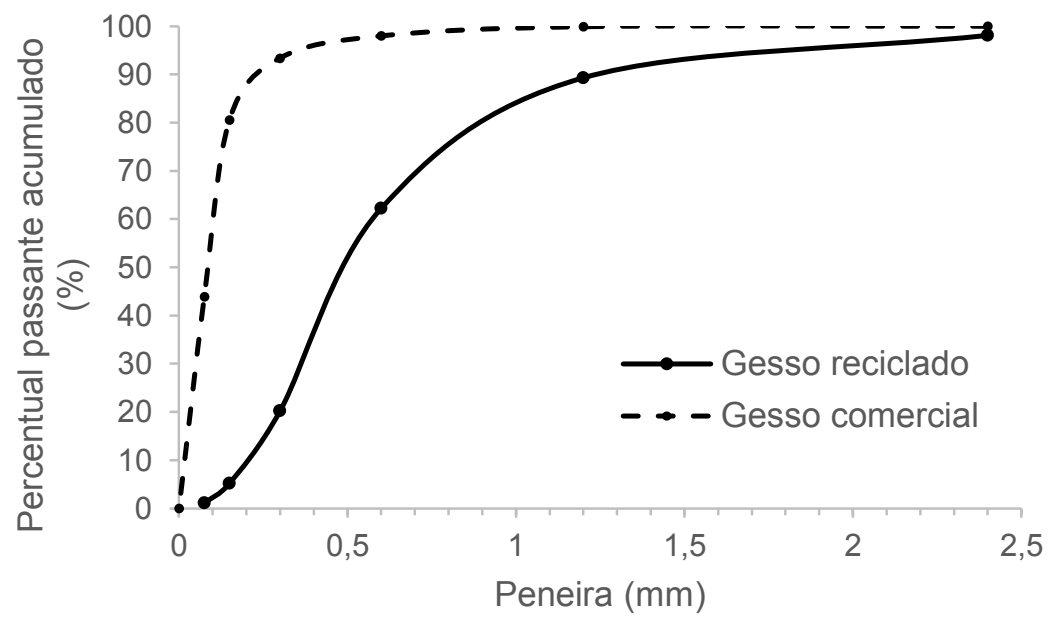

Fonte: Autores (2015)

A partir da distribuição granulométrica das duas amostras foram calculados os módulos de finura dos dois materiais. O gesso comercial apresenta módulo de finura igual a 0,19 enquanto o gesso reciclado apresenta módulo de finura de 2,25 , equivalente ao de uma areia fina. É importante destacar também que a distribuição granulométrica do gesso reciclado é uma distribuição granulométrica contínua enquanto a distribuição granulométrica do gesso comercial por ser composta majoritariamente por poucas 


\section{REA - Revista de estudos ambientais (Online) v.17, n. 2, p.60-73, jul./dez. 2015}

peneiras pode ser classificada como descontínua.

\subsubsection{Consistência da pasta do gesso reciclado}

A consistência da pasta é um parâmetro bastante importante, pois é indicativo da maior ou menor trabalhabilidade do material.

Comparando-se o comportamento do gesso reciclado e do gesso comercial é notório que o gesso reciclado não apresenta um comportamento linear entre o consumo de água e a consistencia (Figura 7). Esse fato pode ser explicado pela presença de maior quantidade de partículas com dimensões maiores no material reciclado, que são prejudiciais à consistência. Já para quantidades mais elevadas de água a consistência apresentou-se superior a do gesso comercial. De maneira análoga esse comportamento se deve a menor área superficial do gesso reciclado, uma vez que o mesmo apresenta particulas maiores. A área superficial é diretamente proporcional a água adsorvida da superfície das particulas, assim quanto menor a área superficial mais água livre entre as partículas contribuindo com o aumento da consistência. Já a consistência da pasta de gesso comercial em função do consumo de água apresenta comportamento aproximadamente linear.

Figura 7 - Cosistência da pasta de gesso para diferentes quantidades de água por kg de gesso

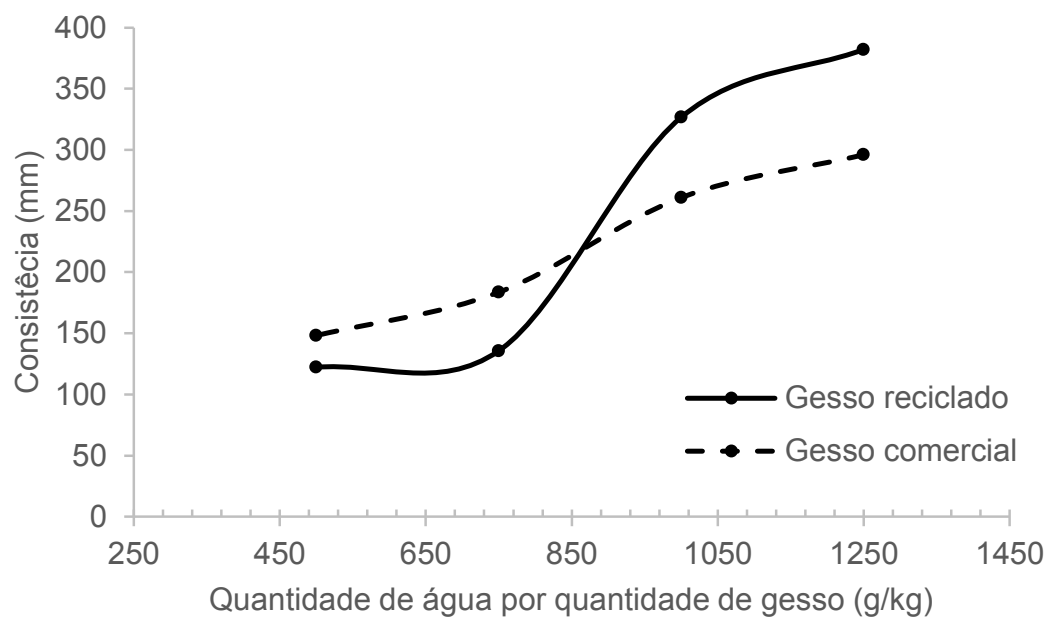

Fonte: Autores (2015)

\subsubsection{Determinação dos tempos de pega do gesso reciclado}

A NBR 13207 (ABNT, 1994) que estabelece as exigencias físicas do gesso para construção civil classifica o gesso em quatro categorias: fino para revestimento, grosso para revestimento, fino para fundição e grosso para fundição. Segundo os critérios da referida norma o gesso reciclado não atende a exigência para nenhuma classificação quanto ao tempo de início de pega (Figura 8). Isto significa que o mesmo não apresenta os requisitos mínimos necessários para ser empregado em usos convencionais na construção civil. Este fato reforça a importância de se buscar um uso alternativo para o mesmo.

$\mathrm{Da}$ mesma forma que para o tempo de inicio de pega o gesso reciclado não atende as exigências da NBR 13207 (ABNT,
1994) para o tempo de fim de pega (Figura 9).

Comparando o comportamento de início e fim de pega das pastas de gesso reciclado e gesso comercial para todos os consumos de água as pastas de gesso reciclado apresentaram sempre menor tempo tanto de inicio quanto de fim de pega. Destaca-se ainda que para o menor consumo de água o tempo de inicio de pega foi menor que dois minutos o que pode restringir a aplicação do material. Já para os maiores consumos de água o tempo de início de pega medido ficou próximo aos quatro minutos exigidos pela norma NBR 13207 (ABNT, 1994) para o gesso grosso para fundição. 


\section{REA - Revista de estudos ambientais (Online) v.17, n. 2, p.60-73, jul./dez. 2015}

Figura 8 - Tempo de início de pega da pasta de gesso para diferentes quantidades de água por kg de gesso

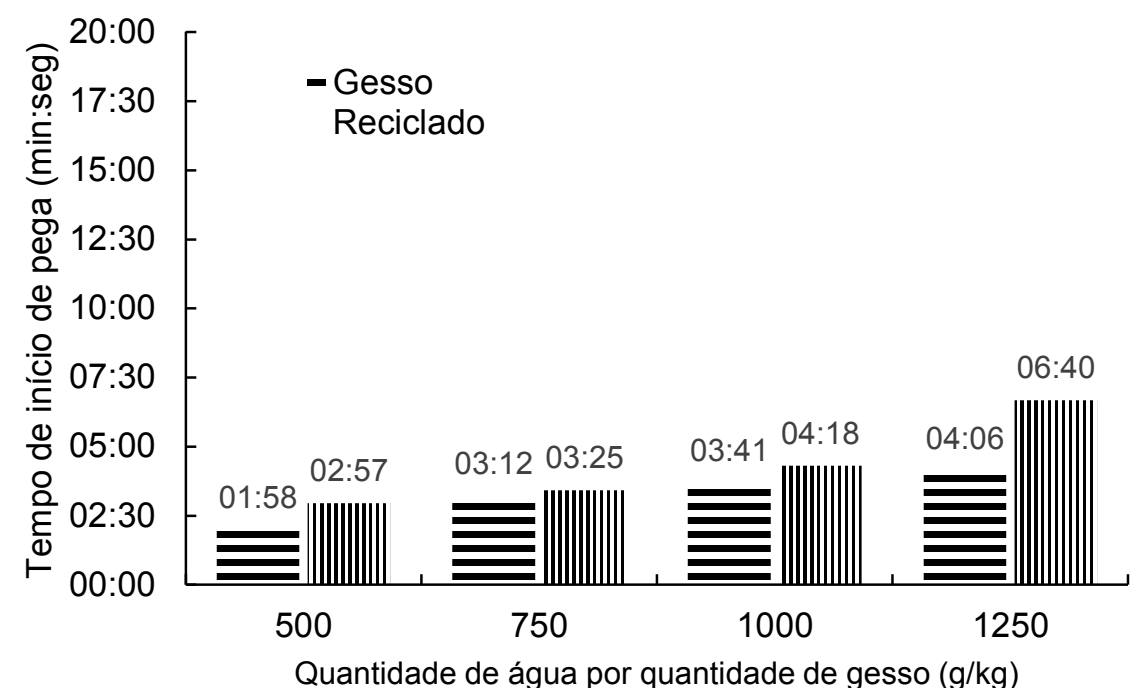

Fonte: Autores (2015)

Figura 9 - Tempo de fim de pega da pasta de gesso para diferentes quantidades de água por kg de gesso

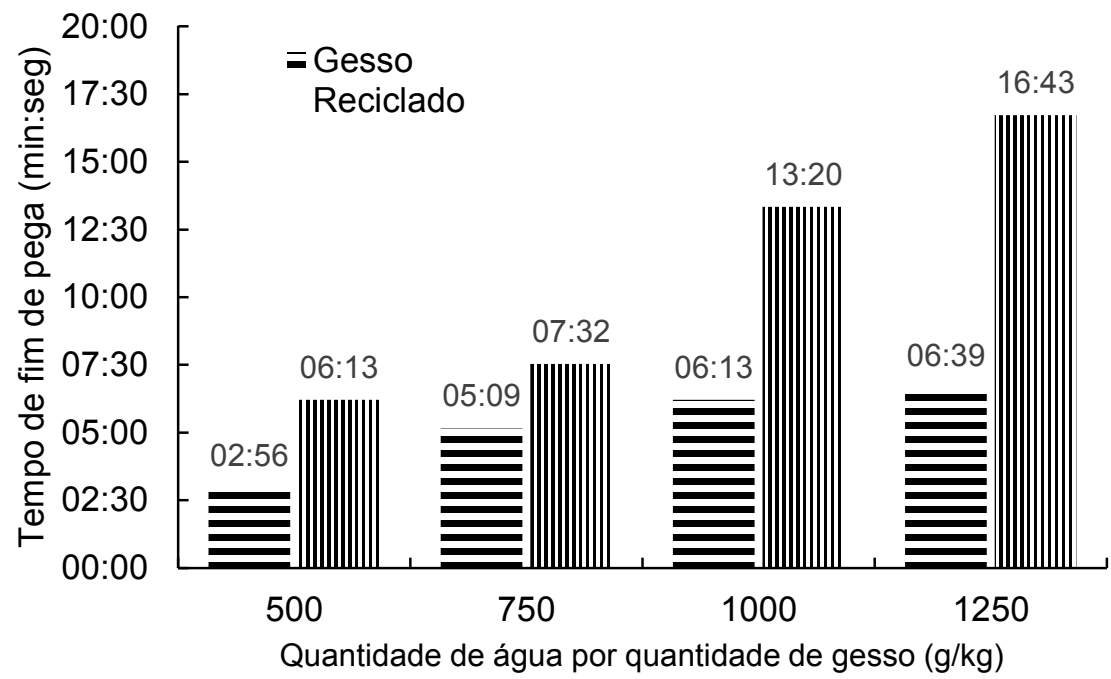

Fonte: Autores (2015)

\subsubsection{Resistência à tração na flexão da pasta de gesso reciclado}

No caso da pasta de gesso comercial a diminuição da quantidade de água por quantidade de gesso impactou positivamente na resistência à tração na

Já para a pasta produzida a partir do gesso reciclado notam-se valores superiores de resistência à flexão. Estes foram gerados pelo maior empacotamento das particulas uma vez que a distribuição granulométrica do gesso reciclado é contínua enquanto a distribuição granular do gesso comercial é descontínua. Para o menor consumo de flexão (Figura 10). Ao se passar de um consumo de 1.000 gramas de água para 500 gramas de água por quilograma de gesso comercial a resistência foi aumentada cinco vezes, passando de 0,65 para 3,35 MPa. O crescimento apresentou um comportamento exponencial frente ao consumo de água. água, no entanto, ocorre uma inversão, a pasta produzida com o gesso comercial apresenta resistência à tração na flexão maior do que a produzida a partir do gesso reciclado. Esse fato é justificado pela baixa consistência da mistura que implica na maior dificuldade de moldagem. Como a energia de compactação dos corpos de prova é 


\section{REA - Revista de estudos ambientais (Online) v.17, n. 2, p.60-73, jul./dez. 2015}

padronizada, a pouca trabalhabilidade gera defeitos internos no material, como poros compostos por ar incorporado, que diminuem a resistência à tração do material.

Figura 10 - Resistência à tração na flexão da pasta de gesso para diferentes quantidades de água por quantidade de gesso

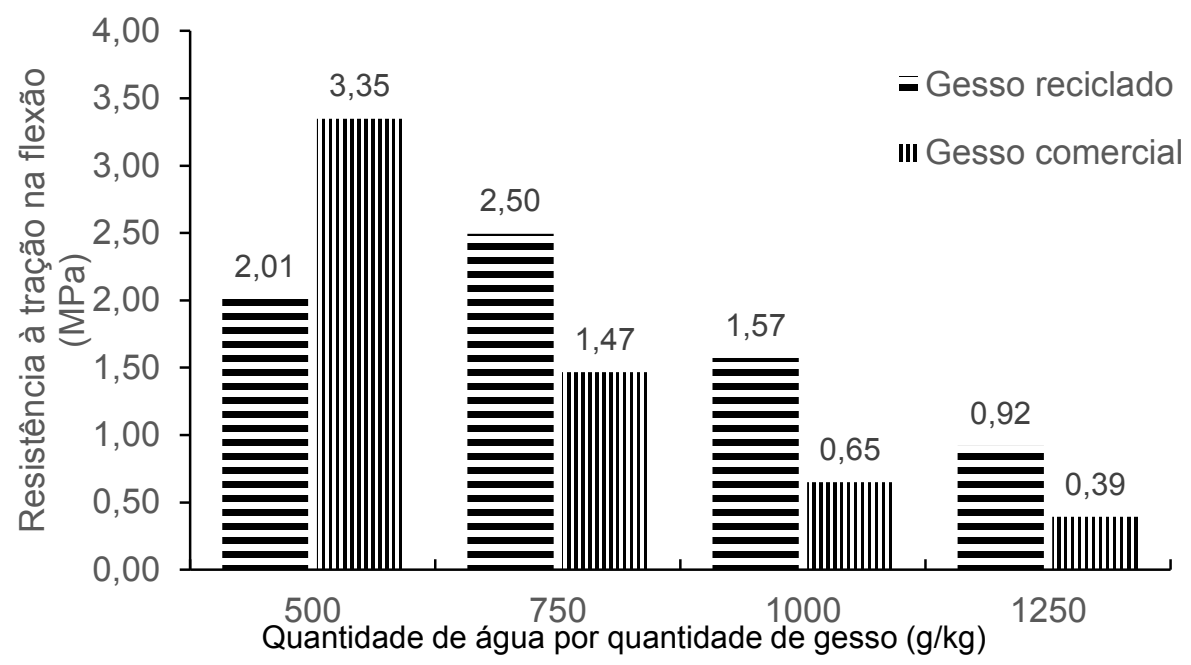

Fonte: Autores (2015)

\subsubsection{Resistência à compressão da pasta de gesso reciclado}

A resistência à compressão apresenta-se inversamente proporcional a quantidade de água (Figura 11). Para todas as quantidades de água de mistura a resistência à compressão do gesso reciclado apresentou-se maior do que a do gesso comercial. Esse fato se deve ao maior empacotamento das partículas do material reciclado, característico das distribuições granulométricas contínuas.

Apesar de apresentar resistência superior as pastas de gesso comercial nenhuma das pastas de gesso reciclado apresenta resistência mínima exigida pela NBR 12129 (ABNT, 1991) de 8,4 MPa para gesso destinado à construção civil.

Figura 11 - Resistência à compressão da pasta de gesso para diferentes quantidades de água por kg de gesso

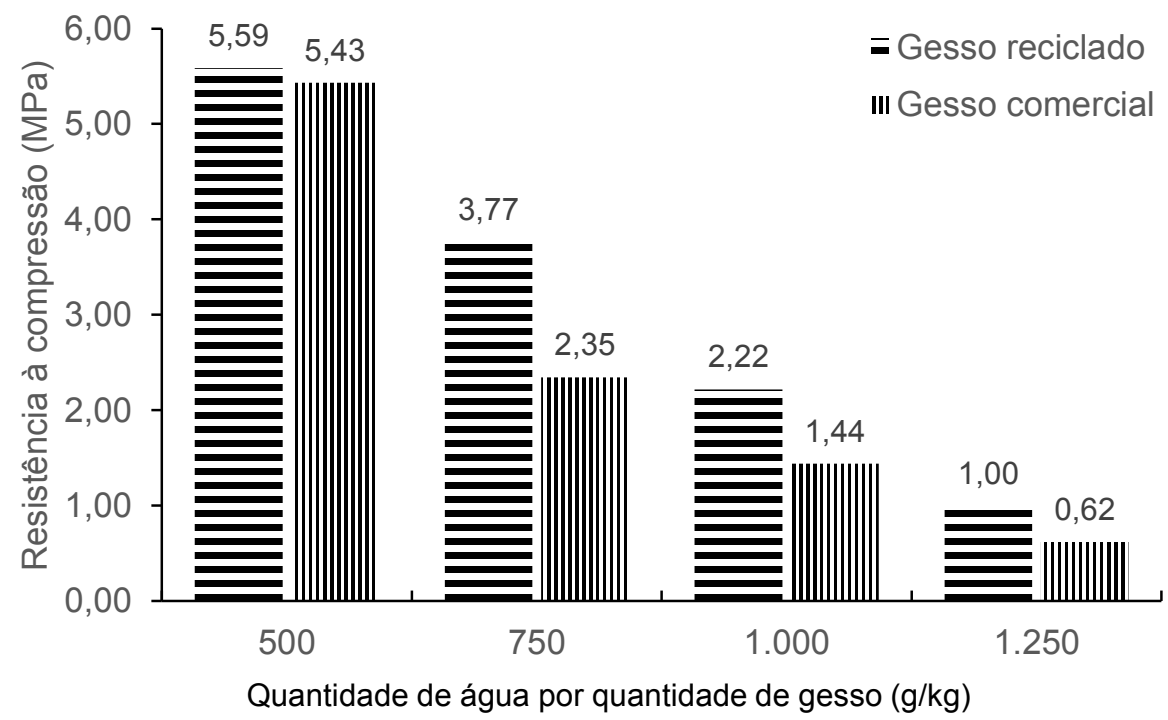

Fonte: Autores (2015) 


\section{REA - Revista de estudos ambientais (Online) v.17, n. 2, p.60-73, jul./dez. 2015}

\subsection{Composito de gesso e EPS reciclados}

A partir dos resultados obtidos elegeu-se como pasta mais adequada para ser empregada na produção do composito de gesso e EPS reciclados a pasta com 1.000 gramas de água para cada quilograma de gesso reciclado. Essa proporção de gesso reciclado apresentou consistência superior a $300 \mathrm{~mm}$, fundamental para a incorporação do EPS, bem como tempo de início de pega próximo à 4 min suficiente para a moldagem de placas.

O composito de gesso e EPS reciclado foi, então, produzido de acordo com as quantidades de material apresentados na Tabela 2 .

Observa-se que na Figura 12 (a) o composito produzido com adição de 5 gramas de EPS encontra-se homogeneamente distribuido ao longo da matriz de pasta de gesso assim como no composito produzido com adição de 10 gramas de EPS (Figura 12 b). Destaca-se que a desmoldagem da placa foi realizada com êxito, para ambos, 24 horas depois da moldagem.

Já para o compósito produzido com adição de 15 gramas de EPS (Figura 12 c) a superfície superior da placa apresentou-se irregular, não apresentando, assim, altura constante. Outro problema apresentado por esse compósito foi a dificuldade na desmoldagem. As peças ao serem desmoldadas tiveram suas extremidades quebradas, apesar de o processo ter sido realizado com cuidado.

Figura 12 - Seção transversal das placas moldadas com compósito de pasta de gesso e EPS reciclados com (a) $5 \mathrm{~g}$; (b) $10 \mathrm{~g} \mathrm{e} \mathrm{(c)} 15 \mathrm{~g}$ de EPS por $\mathrm{kg}$ de gesso reciclado
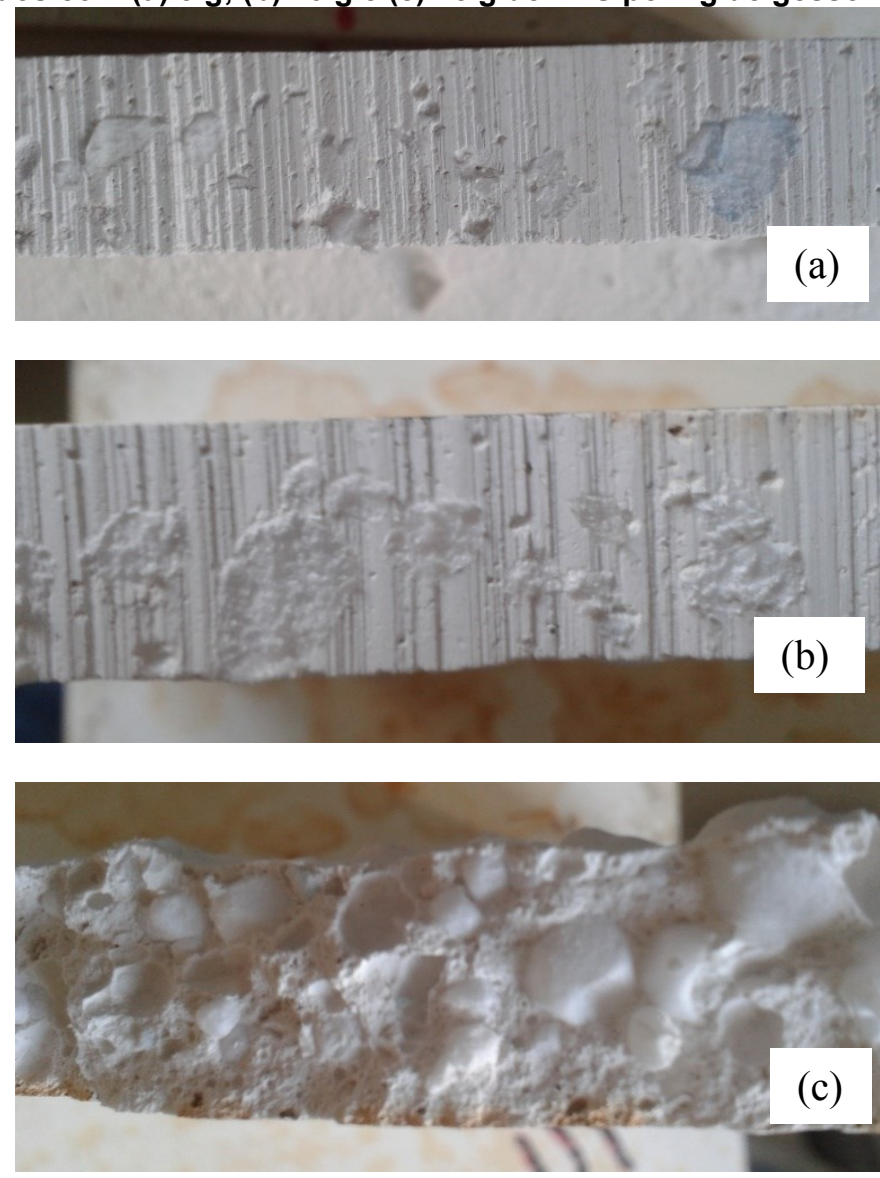

Fonte: Autores (2015)

Pelo fato de o composito produzido com 15 gramas de EPS por quilograma de gesso reciclado apresentar problemas de desforma e também dificuldades de conformação o mesmo não se apresenta em condições de ser utilizado na produção de placas. Assim sendo o mesmo não foi caracterizado quanto a sua resistência à tração na flexão e massa específica. 


\section{REA - Revista de estudos ambientais (Online) v.17, n. 2, p.60-73, jul./dez. 2015}

\subsubsection{Determinação da resistência à tração na flexão}

A norma NBR 12775 (ABNT, 1992) determina as dimensões e propriedades físicas das placas lisas de gesso para forro, contudo a norma não fixa uma resistência mínima à tração na flexão para as placas de gesso. A resistência à compressão das placas produzidas com compósito de gesso e EPS apresentou uma diminuição média de $30 \%$ comparada a placa produzida somente com gesso (Tabela 3 ).

Tabela 3 - Resistência à tração na flexão das placas produzidas com compósitos de gesso e EPS reciclados

\begin{tabular}{c|c|c}
\hline $\begin{array}{c}\text { Quantidade de EPS }(\mathrm{g}) \text { por } \\
\text { quantidade de gesso reciclado }(\mathrm{kg})\end{array}$ & $\begin{array}{c}\text { Valor médio } \\
(\mathrm{MPa})\end{array}$ & $\begin{array}{c}\text { Desvio Padrão } \\
(\mathrm{MPa})\end{array}$ \\
\hline 0 & 1,22 & 0,65 \\
\hline 5 & 0,86 & 0,35 \\
\hline 10 & 0,90 & 0,44 \\
\hline
\end{tabular}

Fonte: Autores (2015)

\subsubsection{Determinação da massa específica}

A adição de 10 gramas de EPS por quilograma de gesso impactou na diminuição da massa específica de 48\% (Figura 13), já a adição de 5 gramas de EPS por quilograma de gesso diminuiu a massa específica da placa em $38 \%$.

Haja vista a diminuição da massa específica ser mais acentuada para a adição de 10 gramas de EPS por quilograma de gesso, e essa adição não representar um decrescimo acentuado da resistência à tração na flexão este mostrou ser o compósito mais adequado a produção de placas para revestimento de forro.

Figura 13 - Massa específica do compósito para diferentes adições de EPS por kg de gesso reciclado

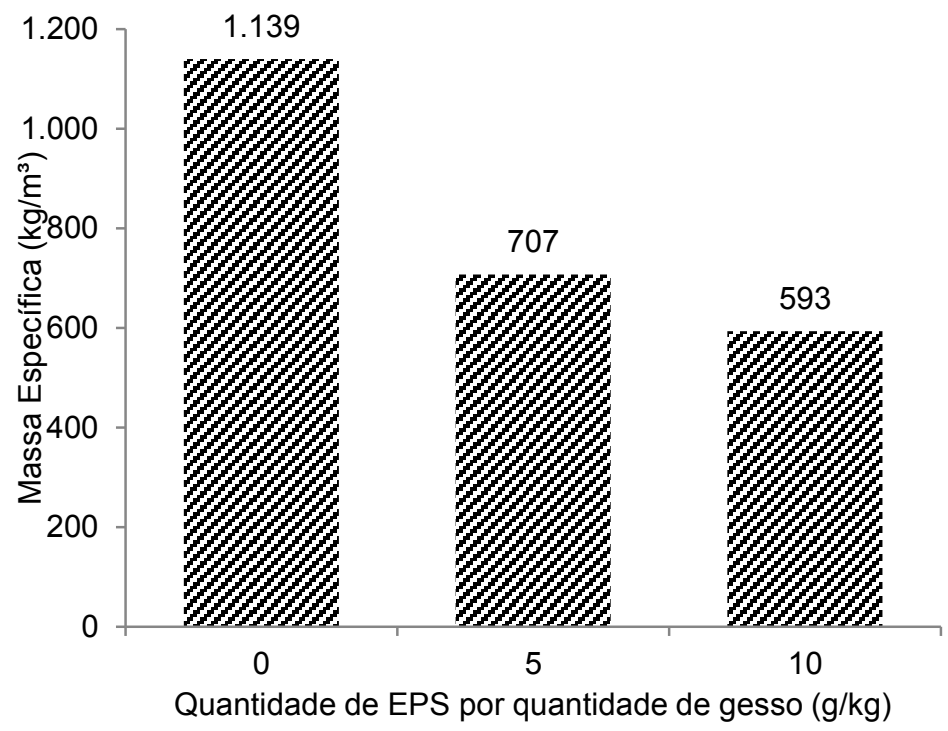

Fonte: Autores (2015)

\section{Conclusões}

O presente trabalho demostrou que é possivel a moldagem de elementos utilizando os materiais reciclados de gesso e EPS, desde que, sejam processados corretamente. $O$ fato de as placas serem totalmente provenientes de residuo da construção as torna muito atrativas quanto ao quesito sustentabilidade, pois ambos os 
materiais utilizados são de dificil destinação final. As placas consideradas ideais, ou seja, com as melhores combinações de EPS e gesso reciclado apresentaram uma redução bastante consideravel de peso do elemento moldado. A substituição de parte da massa de gesso reciclado por EPS reciclado, nao alterou muito a resistencia à tração na flexão final. Este é um aspecto bastante importante visto que este é um elemento de acabamento e nao possui caracteristicas estruturais.

O gesso reciclado segundo 0 tratamento utilizado neste estudo apresentou módulo de finura, tempos de pega e resistência a compressão que não atendem as exigencias normativas como gesso para construção civil.

Sugere-se como indicação para trabalhos futuros a aplicação de outros procedimentos de tratamento do resíduo de gesso buscando otimizar principalmente 0 processo de moagem do resíduo e de calcinação do mesmo. Buscando aumentar o tempo de início de pega da pasta de gesso reciclada, diminuir o tempo de moagem do resíduo e também diminuir o tempo de calcinação.

\title{
5 Liner Boards Produced With a Composite of Gypsum and EPS Recycled
}

\begin{abstract}
Gypsum and Expanded Polystyrene (EPS) are widely used in construction. Despite being wellknown building materials, technologies to reintroduce their wastes into the constructive chain still face challenges. The aim of this study was to develop liner boards produced with a composite made of gypsum and EPS recycled. Methodology includes characterization, processing and comparison of the recycled gypsum with the commercial gypsum, according to standards requirements. Then, the behavior of recycled gypsum plasters regarding water/gypsum ratio was evaluated and a composite with 5, 10 and $15 \mathrm{~g}$ of recycled EPS was produced. Liner boards were then made and experiments are realized to determine flexural tensile strength and density. Results show that recycled gypsum plaster with water/gypsum ratio of 1 and the composites with 5 and $10 \mathrm{~g}$ of recycled EPS are suitable to produce ceiling lining boards regarding flexural tensile strength and density.
\end{abstract}

Keywords: Waste; EPS; Gypsum; Liner boards.

\section{Referências}

ASSOCIAÇÃO BRASILEIRA DE NORMAS TÉCNICAS. NM 65: Cimento Portland Determinação do tempo de pega. Rio de Janeiro, 2002.

ASSOCIAÇÃO BRASILEIRA DE NORMAS TÉCNICAS. NM 248: Agregados - Determinação da composição granulométrica. Rio de Janeiro, 2001.

ASSOCIAÇÃO BRASILEIRA DE NORMAS TÉCNICAS. NBR 12129: Gesso para construção - Determinação das Propriedades mecânicas Método de ensaio. Rio de Janeiro, 1991.

ASSOCIAÇÃO BRASILEIRA DE NORMAS TÉCNICAS. NBR 12775: Placas Lisas de Gesso para Forro - Determinação das Dimensões e Propriedades Físicas. Rio de Janeiro, 1992.

ASSOCIAÇÃO BRASILEIRA DE NORMAS TÉCNICAS. NBR 13207: Gesso Para Construção Civil. Rio de Janeiro, 1994.

ASSOCIAÇÃO BRASILEIRA DE NORMAS TÉCNICAS. NBR 13276: Argamassa para
Assentamento e Revestimento de Paredes e Tetos - Preparo da Mistura e Determinação do Índice de Consistência. Rio de Janeiro, 2005.

ASSOCIAÇÃO BRASILEIRA DE NORMAS TÉCNICAS. NBR 13279: Argamassa para Assentamento e Revestimento de Paredes e Tetos - Determinação da resistência à tração na flexão e à compressão. Rio de Janeiro, 2005.

ASSOCIAÇÃO BRASILEIRA DE NORMAS TÉCNICAS. NBR 13528: Revestimento de paredes e tetos de argamassas inorgânicas Determinação da resistência de aderência à tração. Rio de Janeiro, 2010.

ASSOCIAÇÃO BRASILEIRA DO DRYWALL, 2015. Números do Segmento Gesseiro. Disponível em: <http://www.abragesso.org.br/index.php/6/numero s-do-segmento>. Acesso em: 27 dez. 2015.

ASSOCIAÇÃO BRASILEIRA DO DRYWALL, 2012. Resíduos de gesso na construção civil Coleta, armazenagem e destinação para reciclagem. Disponível em: <http://www.mma.gov.br/port/conama/processos/1 


\section{REA - Revista de estudos ambientais (Online) v.17, n. 2, p.60-73, jul./dez. 2015}

8018FE8/Cartilha_Residuosgesso.pdf $>$. Acesso em: Acesso em: 27 dez. 2015.

BRASIL. Departamento Nacional de Produção Mineral. Ministério de Minas e Energia. Sumário mineral brasileiro de 2013. Brasil: DNPM, 2009. Disponível em: <http://www.dnpm.gov.br/dnpm/sumarios/sumariomineral-2014>. Acesso em: Acesso em: $27 \mathrm{dez}$. 2015.

CONSELHO NACIONAL DO MEIO AMBIENTECONAMA. Resolução n. 307, de 5 de julho de 2002. Estabelece diretrizes, critérios e procedimentos para a gestão dos resíduos da construção civil. Disponível em: <http://www.mma.gov.br/port/conama/legiabre.cfm ?codlegi=307>. Acesso em: Acesso em: $27 \mathrm{dez}$. 2015.

CONSELHO NACIONAL DO MEIO AMBIENTECONAMA. Resolução n. 431, de 24 de maio de 2011. Altera o art. 3o da Resolução no 307/ 2002. Disponível em: <http://www.mma.gov.br/port/conama/legiabre.cfm ?codlegi=649>. Acesso em: 27 dez. 2015.

GROTE, Z. V.; LUZ-SILVEIRA, J.; BITTENCOURT, R. M. A influência da utilização de poliestireno expandido - EPS na conservação de energia aplicado em edificações e sua reciclagem. In: Encontro Nacional de Conforto no Ambiente Construído, 5.,1999, Fortaleza. Anais... 1999.

MEDEIROS, D. S.; OLIVEIRA NETO, M. L.; OLIVEIRA, M. M. F.; MARINHO, G. S. Reaproveitamento de EPS para isolamento térmico de cobertura. In: Simpósio: Desempenho Térmico de Sistemas Construtivos Alternativos, 2003, Natal. Anais ... 2003.

MESQUITA, L. S. P.; PÓVOAS, Y. V. Influência de aditivo retardador de pega na pasta de gesso com resíduo de gesso calcinado. In: Encontro Nacional de Tecnologia do Ambiente Construído, 15, 2014, Maceió. Anais... 2014.

MONTEIRO, R. S.; MELO, K. A.; UCHÔA, S. B. B. Geração de resíduos de gesso em empresas de construção civil de Maceió - AL. In: Encontro Nacional de Tecnologia do Ambiente Construído, 13, 2010, Canela. Anais ... 2010.

MOURA, R. S. L. M.; DEUSDARA, D. F. M.; BARRETO, J. M. L.; CABRAL, A. E. B. Avaliação da adequação do gesso reciclado às prescrições da NBR 13207. Encontro Nacional de Tecnologia do Ambiente Construído, 15., 2014, Maceió. Anais .... 2014.

NASCIMENTO, F. J. F.; PIMENTEL, L. L. Reaproveitamento de resíduo de gesso. Encontro Nacional de Tecnologia do Ambiente Construído, 13, 2010, Canela. Anais ... 2010.

NITA, C.; PILEGGI, R. G.; CINCOTTO. M. A.; JOHN, V. M. Estudo da Reciclagem do Gesso de Construção. Conferência Latino-Americana de Construção Sustentável, 1. -Encontro Nacional de Tecnologia do Ambiente Construído, 10., 2004, São Paulo. Anais ... 2004

PINHEIRO, S. M. de M. Gesso reciclado: avaliação das propriedades para uso em componentes. 2011. 304 p. Tese (Programa de Pós- Graduação em Engenharia Civil) Faculdade de Engenharia Civil, Universidade Estadual de Campinas, Campinas, 2011.

SALES, A. T. C.; SANTOS, D. G.; RIBEIRO, K. F. Resistência à flexão e aderência de pasta de gesso obtida por reciclagem de resíduos. Encontro Nacional de Tecnologia do Ambiente Construído, 15, 2014, Maceió. Anais... 2014.

SINDUSGESSO - Sindicato da Indústria do gesso do Estado de Pernambuco. Crescimento econômico do polo gesseiro nos últimos seis anos. 2014. Disponível em: $<$ http://www.sindusgesso.org.br/crescimentoeconomico-do-polo-gesseiro-nos-ultimos-seisanos/>. Acesso em: 27 dez. 2015.

SIQUEIRA, L. V.; STRAMARI, M. R.; FOLGUERAS, M. V. Adição de poliuretano expandido para a confecção de blocos de concreto leve. Revista Matéria, v. 9, n. 4, p. 399410, 2004.

STOCCO, W.; RODRIGUES, D.; CASTRO, A. P. A. S. Concreto leve com uso de EPS. Congresso Brasileiro de Educação em Engenharia, 2009, Recife. Anais ... 2009.

TAVARES, Y. V. P.; LORDSLEEM JÚNIOR, A. C.; SCHMITZ, I. B. T. A.; JOHN, V. M. Reaproveitamento do resíduo de gesso na execução de revestimento interno de vedação vertical. Ambiente Construído, Porto Alegre, v. 10, n. 1, p. 103-119, jan./mar., 2010. 